\title{
Experimental characterization of gasoline sprays under highly evaporating conditions
}

\author{
Muhammad Mahabat Khan ${ }^{1,2,3^{*}}$, Nadeem Ahmed Sheikh ${ }^{3}$, Azfar Khalid ${ }^{1}$, Waqas Akbar Lughmani ${ }^{1}$ \\ ${ }^{I}$ Department of Mechanical Engineering, Capital University of Science and Technology, Islamabad, Pakistan \\ ${ }^{2}$ Laboratoire de Mécanique des Fluides et d'Acoustique, Ecole Centrale de Lyon, France \\ ${ }^{3}$ Department of Mechanical Engineering, HITEC University, Taxila, Pakistan
}

*Corresponding Author email: drmahabat@cust.edu.pk

\begin{abstract}
An experimental investigation of multistream gasoline sprays under highly evaporating conditions is carried out in this paper. Temperature increase of fuel and low engine pressure could lead to flash boiling. The spray shape is normally modified significantly under flash boiling conditions. The spray plumes expansion along with reduction in the axial momentum causes the jets to merge and creates a low-pressure area below the injector's nozzle. These effects initiate the collapse of spray cone and lead to the formation of a single jet plume or a big cluster like structure. The collapsing sprays reduces exposed surface and therefore they last longer and subsequently penetrate more. Spray plume momentum increase, jet plume reduction and spray target widening could delay or prevent the closure condition and limit the penetration (delayed formation of the cluster promotes evaporation). These spray characteristics are investigated experimentally using shadowgraphy, for five and six hole injectors, under various boundary conditions. Six hole injectors produce more collapsing sprays in comparison to five hole injector due to enhanced jet to jet interactions. The spray collapse tendency reduces with increase in injection pressure due high axial momentum of spray plumes. The spray evaporation rates of five hole injector are observed to be higher than six hole injectors. Larger spray cone angles of the six hole injectors promote less penetrating and less collapsing sprays.
\end{abstract}

Keywords: Multihole injector; Flash boiling; Spray collapse, shadowgraphy

\section{Introduction}

Today the goal of automotive industry is to increase the engine performance and reduce the emissions especially $\mathrm{CO}_{2}$ in case of SI engines. For this purpose, engine downsizing, along with variable valve timing and turbo charging have been introduced. But the most significant component that 
allowed the automotive industry to achieve the goal of high performing engines with reduced emissions is gasoline direct injection (GDI) injector. GDI fuel injectors allow the spark ignition engines to achieve higher compression ratios while ensuring lean burning and low pumping and heat losses [1]. GDI injectors are multihole injectors which inject multiple fuel streams or sprays directly in the engine allowing it to operate in homogeneous conditions [2]. Multiple spray plumes increase the surface area of the fuel that promotes evaporation and helps in formation of better air fuel mixture. However, multiple spray plumes can interact with each other under certain conditions. The spray interactions can lead to spray cone collapse resulting in high penetrating and less evaporating spray. Uncontrolled spray collapse can decrease engine performance and increase pollutant emissions. Therefore, it is essential to investigate the factors and conditions that can affect the performance of GDI sprays.

In the past, numerous experimental studies have been performed to investigate different characteristics of GDI sprays. The atomization of GDI sprays has been focused for quite some time, for instance $[3,4]$. The evaporation characteristics of GDI sprays are investigated by [5-8]. The flow properties at the exit of injection hole under non-evaporating and low fuel pressure are investigated by [9]. The effect of number of injection holes on the diesel spray mixing and eventually on the combustion efficiency have been studied by [10]. The increase in the number of injection holes promote the spray interactions leading to poor mixture formation. The injection pressure used in that study is of similar range as in real life gasoline sprays in engines. However, the chamber pressures are much higher in comparison to the gasoline engine condition due the difference of compression ignition in diesel engines and spark ignition is gasoline engines. GDI sprays have been observed to show a collapsing effect under highly evaporating conditions [11, 12]. The collapsing effect has been observed to be more pronounced in flash boiling conditions where the super-heated fuel causes the spray to expand instantly during the spray injection process especially under low chamber pressure [13].

Besides engine conditions, the injector design is also an important factor that can influence he spray characteristics. The two most important parameters are spray cone angle and the number of injection holes that are also highlighted in $[8,9]$. Both of these parameters are linked to the engine design constraints e.g. engine size, injector location, injection timing with respect to piston and valve movements. Usually it becomes very difficult to optimize the injector performance while keeping the constraints in mind. Therefore, it is necessary to have clear understanding of the injector parameters in different ambient conditions, especially under evaporating and non-evaporating conditions. The factors that affect the spray behavior have been summarized by a flow chart presented in Figure 1 . 
For this purpose, four different configurations of multihole GDI injectors are selected. These injectors are tested under highly evaporating conditions (flash boiling conditions), moderate evaporating conditions (non-flash boiling conditions) and lastly under ambient conditions (non-evaporating conditions). The fuel is injected at different injection pressure and temperatures in a constant volume chamber. High-speed shadowgraphy is used to capture the spray features under different injection and chamber conditions.

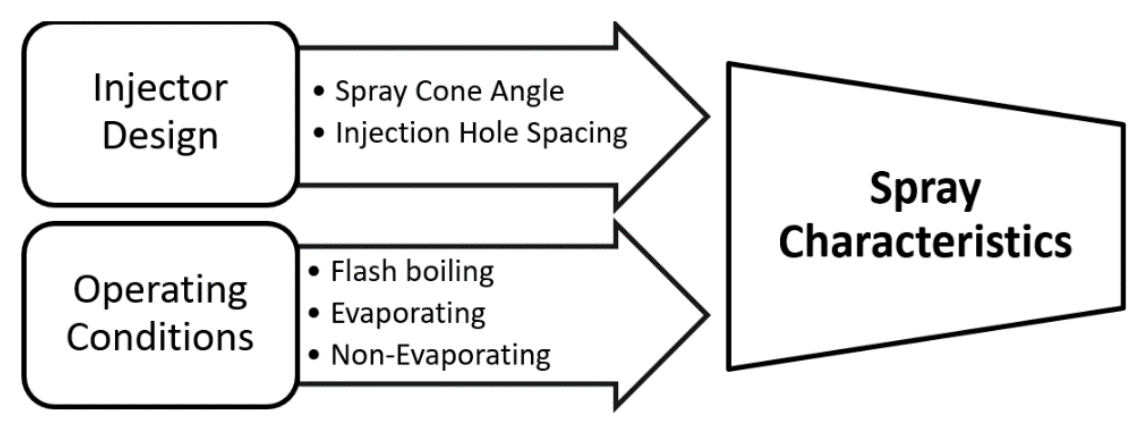

Figure 1: A Flow chart of factors effecting the spray characteristics of multistream injector

\section{Experimental Setup:}

Experimental setup used in this study is detailed in this section.

\subsection{Injector Design}

A schematic of a cross-sectional plane of a typical GDI injector nozzle is presented in Figure 2 (a). The injection hole length is represented by Li and the diameter of injection hole is denoted by Di. The half injector cone angle is denoted by $\beta$ which measured for the center of the injection hole to the central axis of the injector. The injection hole length to injection hole diameter ratio (Li/Di) is usually close to 1 in order to get stable spray jets. Therefore, in all four injectors Li/Di ratio is kept constant at 1.1. The injector holes are located symmetrically being $30 \mathrm{o}$ apart. The radius of the injector nozzle is $600 \mu \mathrm{m}$ and the radius of injection holes are $100 \mu \mathrm{m}$.

Four different injectors are used in this study. Three injectors are 6-hole injector while the fourth injector is 5-hole injector. All three variants of 6-hole injectors have same injection holes locations but different spray cone angles as presented in Table 1. The 6-hole injector version 1 (V1)

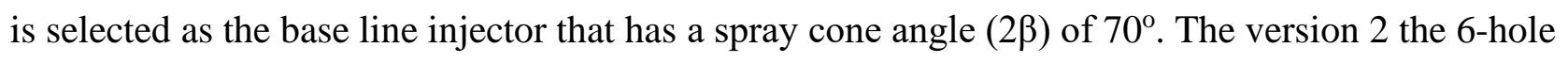
injector (V2) has a spray cone angle of $60^{\circ}$ while the version 3 (V3) has a spray cone angle of $50^{\circ}$. 
The spray cone angle variations correspond to realistic spray cone angles found in real life engines. Usually, the spray cone angles vary from engine to engine depending on the injector placement in the engine and the size of the engine. In some engines the injector is mounted vertically at the top center whereas in other cases spark plug is mounted at the center and the injector is placed on the side. However typical spray cone angles vary from $75^{\circ}$ cone angle to $45^{\circ}$ [6].

The 5-hole injector has same configuration as the base line case except for a missing injection hole as shown in Figure 2 (c). This configuration of the injector is selected to show the variation in the injection hole spacing while keeping the same injector parameters. Therefore, it would be easier to detect the effects of spacing of injection holes due to asymmetry in the jets.

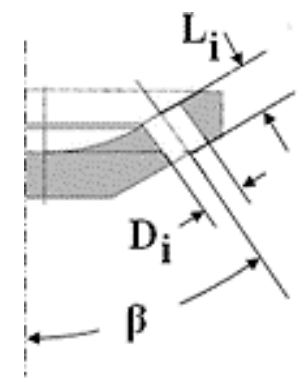

(a)

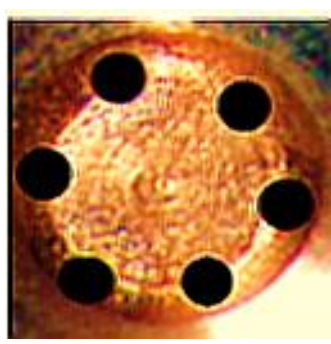

(b)

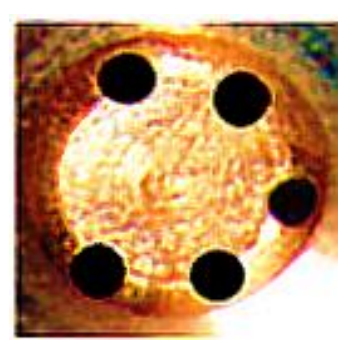

(c)

Figure 2: 6-hole injector design; (a) schematic of vertical cross-section of the injector nozzle; (b) nozzle of 6-hole injector (c) nozzle of 5-hole injector

\begin{tabular}{|c|c|c|}
\hline Injector Type & $\begin{array}{c}\text { Nozzle } \\
\text { Radius }(\boldsymbol{\mu m})\end{array}$ & $\begin{array}{c}\text { Spray Cone Angle } \\
(\mathbf{2} \boldsymbol{\beta})\end{array}$ \\
\hline 6 hole V1 & $\mathbf{6 0 0}$ & $\mathbf{7 0}^{\mathbf{0}}$ \\
\hline 6 hole V2 & $\mathbf{6 0 0}$ & $\mathbf{6 0}^{\mathbf{0}}$ \\
\hline 6 hole V3 & $\mathbf{6 0 0}$ & $\mathbf{5 0}^{\mathbf{0}}$ \\
\hline 5 hole & $\mathbf{6 0 0}$ & $\mathbf{7 0}^{\mathbf{0}}$ \\
\hline
\end{tabular}

Table 1: Nozzle configurations of different injectors

The role of injection spray cone angles in the atomization enhancement under flash boiling conditions have been highlighted in [14]. The study of morphology of spray for five hole injector under various flashing and non-flashing in [15] highlights the importance of spray cone angle. The distance between the injection holes is also an important parameter that play a crucial role in spray characteristics [8]. The spray characteristics based on the gas entrainment of a three hole injector is compared with 6 hole injector in [11]. It was observed that six-hole injector partially collapsed under moderate evaporating conditions while three-hole injector did not collapse. However, those results were not conclusive since the flow physics of six hole and three-hole injectors are completely different. 
Therefore, as stated earlier, the spray cone angle and the distance between the injection holes are two very important parameters. Consequently, three variants of 6-hole injector are used to compare the effect of spray plume angles on the spray characteristics. The 6-hole injector V1 has the largest spray cone angle while 6-hole V3 has smallest spray cone angle. Therefore, injector V1 has a larger radial velocity component of spray plumes in comparison to its other counter parts, V2 and V3. The comparison of these three injectors under various conditions would allow us understand the effects of increased spray cone angles. Under flash boiling conditions multi-hole injectors are prone to collapse therefore it is important to observe the role spray cone angle in the spray collapsing conditions. A five-hole injector with same nozzle radius, hole diameters and a cone angle of $70^{\circ}$ is used. Therefore 6-hole injector V1 and 5-hole injector provide a comparison of injection hole spacing. The fivehole injector has one hole missing on the left as seen in Figure 2 (c). The rest of the injection holes are located at the same positions as in 6-hole injectors. Consequently, the flow physics of five-hole injector will be altered only for the left side.

The Table 2 below shows the summary of the spray parameters that are investigated using different injectors.

\begin{tabular}{|c|l|l|}
\hline Sr. No. & \multicolumn{1}{|c|}{ Injector parameters } & \multicolumn{1}{|c|}{ Injectors used for comparison } \\
\hline 1 & Spray cone angle comparison & 6-hole injector V1, V2, V3 \\
\hline 2 & Injection hole spacing & 6-hole injector V1 and 5-hole injector \\
\hline
\end{tabular}

Table 2: Injector parameters and injectors used for the comparison

\subsection{Fuel Injection System:}

Iso-octane, with a density of $690 \mathrm{~kg} / \mathrm{m}^{3}$, is used as the fuel in the current study. The fuel is supplied to the injector through a hydro pneumatic pump. A flexible pipe which can withstand high pressure connects the pump and the injector. The pump is able to maintain constant pressure throughout the injection process. The pump can inject the fuel from 5 bar to 250 bar. The temporal mass flow rate profile for 6-hole $60^{\circ}$ cone angle injector is provided in Figure 3. 


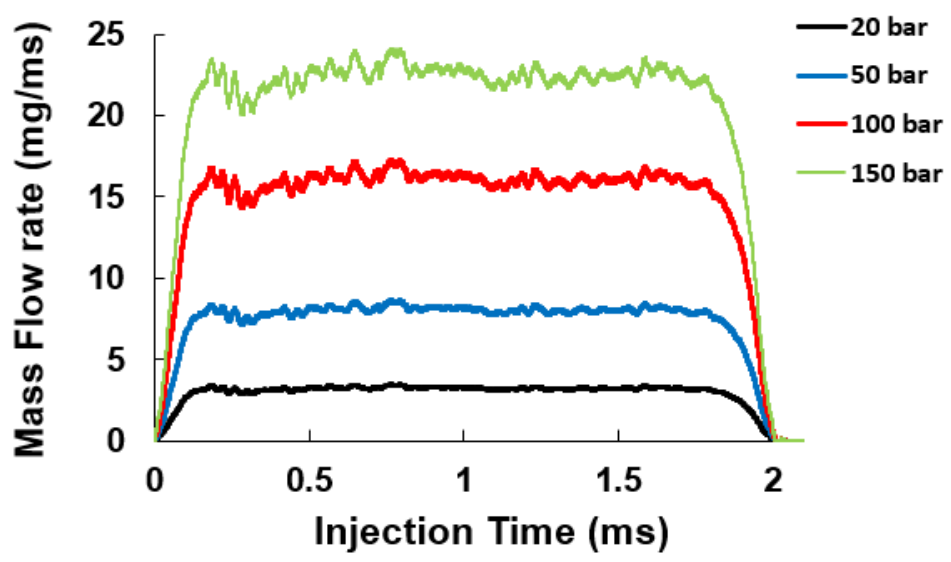

Figure 3: Temporal mass flowrate profile of 6-hole 60injector for various injection pressure under ambient conditions

\subsection{Test Chamber}

The experimental measurements are performed in closed test chamber shown in Figure 4 . The chamber is actually a constant volume chamber of cubical shape of size $100 \mathrm{~mm}$. The test chamber can with stand injection pressure from 1 to 200 bar. The chamber pressure can vary from 0.1 bar to 2 bar and chamber temperature of $20^{\circ} \mathrm{C}$ to $200^{\circ} \mathrm{C}$. The temperature and pressure transducers ensure the accurate measurement of the temperature and pressure respectively. There are five viewing windows installed in the test cell each having a diameter of $50 \mathrm{~mm}$.

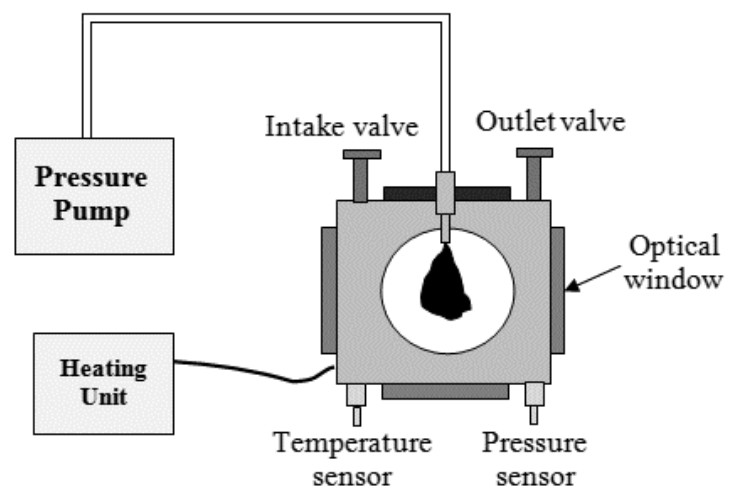

Figure 4 : Schematic of the test chamber

\subsection{Spray imaging Setup}

The shadowgraphic imaging setup is presented in Figure 5. The images of spray are taken by a high speed CCD camera with a field view of $35 \times 50 \mathrm{~mm}$. The CCD camera is equipped with Nikkon $50 \mathrm{~mm}$ lens with an aperture size of approximately $35.72 \mathrm{~mm}$. The camera records 15 images per millisecond. 
The light source is placed on one side of the chamber and camera on the other side. The light source is controlled by a driver and is aligned with optical axis of CCD camera. The light source has a flash duration of 10ns approximately that is small enough to avoid any blurring of the images. The information of the complete setup is provided in the Table 3.

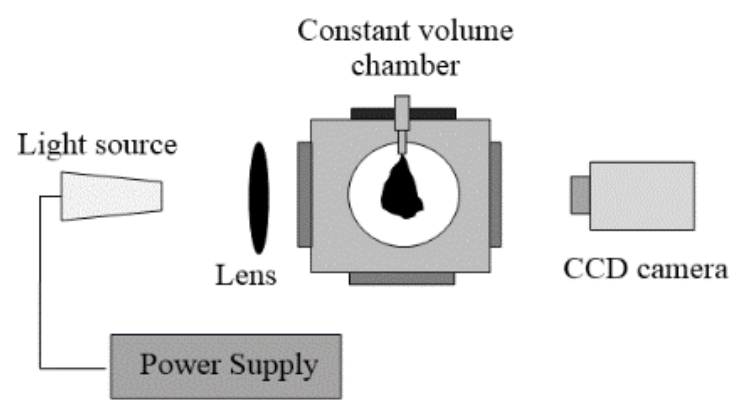

(a)

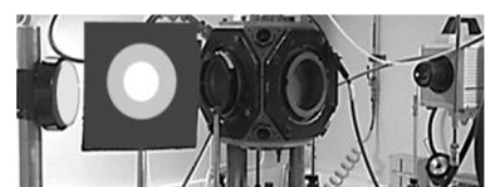

(b)

Figure 5: Optical set up for Shadowgraphic visualisations (a) schematic (b) photograph

Shadowgraphic of sprays for 6-hole $60^{\circ}$ cone angle injectors at 100 bar injection pressure under ambient conditions are presented in Figure 6.

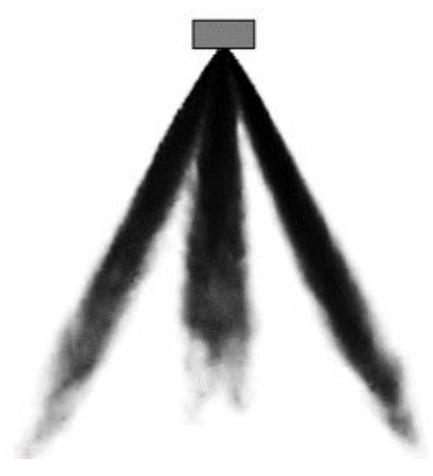

(a)

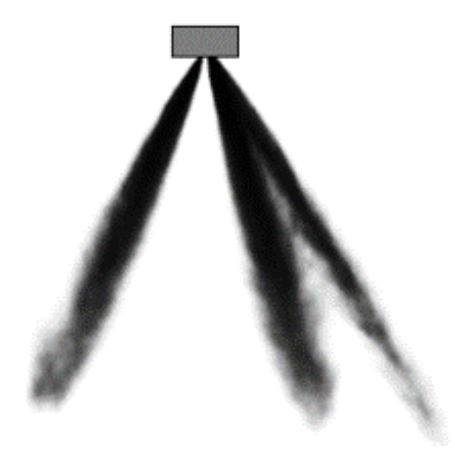

(b)

Figure 6: Shadowgraphic visualisation of spray from (a) 6-hole injector (b) 5-hole injector

\begin{tabular}{|c|c|}
\hline Experimental setup & Specifications \\
\hline Chamber volume & $10^{-3} \mathrm{~m}^{3}(1 \mathrm{~L})$ \\
\hline Chamber pressure range & 0.1 bar to $2 \mathrm{bar}$ \\
\hline Chamber temperature range & $20^{\circ} \mathrm{C}$ to $200^{\circ} \mathrm{C}$ \\
\hline Camera & high speed CCD camera \\
\hline Lens & Nikkon $50 \mathrm{~mm}$ \\
\hline Imaging speed of camera & 15 images per second \\
\hline
\end{tabular}

Table 3: Specifications of experimental setup 


\section{Operating Conditions:}

The operating conditions are provided in the Table 4. There are total number of six operating conditions. The fuel pressure varies from 20 bar to $150 \mathrm{bar}$ and the chamber pressures from $0.4 \mathrm{bar}$ to 1 bar. The fuel temperature varies from $90{ }^{\circ} \mathrm{C}$ to $20^{\circ} \mathrm{C}$ while the chamber temperature is fixed to $20{ }^{\circ} \mathrm{C}$.

\begin{tabular}{|c|c|c|c|}
\hline $\begin{array}{c}\text { Operating } \\
\text { Condition }\end{array}$ & $\begin{array}{c}\text { Fuel } \\
\text { Pressure } \\
\text { (bar) }\end{array}$ & $\begin{array}{c}\text { Chamber Pressure } \\
\text { (bar) }\end{array}$ & $\begin{array}{c}\text { Fuel Temp } \\
\left({ }^{\circ} \mathbf{C}\right)\end{array}$ \\
\hline 1 & 20 & 0.4 & 90 \\
\hline 2 & 50 & 0.4 & 90 \\
\hline 3 & 50 & 0.6 & 60 \\
\hline 4 & 100 & 0.6 & 60 \\
\hline 5 & 100 & 1 & 20 \\
\hline 6 & 150 & 1 & 20 \\
\hline
\end{tabular}

Table 4: Operating conditions

The Figure 7 shows the vapor pressure of iso-octane versus the fuel temperature. The dots represent chamber pressure and fuel temperature of corresponding operating conditions. It is important to note that each set of conditions are selected in such a manner that different spray behaviors could be studied while limiting the number of experiments. The operating condition 1 and 2, as seen in Figure 7 , are representative of flash boiling conditions because the chamber pressure is lower than the fuel vapor pressure at $90^{\circ} \mathrm{C}$. High fuel temperature and low chamber pressure causes multistream sprays to collapse due to spray plume expansion and jet to jet interactions. The collapsing effect is further enhanced because of the reduced axial momentum of the spray due low fuel injection pressure.

The operating condition 3 and 4 are representative of partial spray collapse as the chamber pressure is slightly above the fuel vapor pressure at $60^{\circ} \mathrm{C}$. The operating condition 3 has the same injection pressure as in operating condition 2 but lower fuel temperature and lower chamber pressure. Therefore, at these conditions the axial momentums of the sprays are comparable at both operating conditions 2 and 3 but the effect of fuel temperature and chamber pressure on the spray collapse intensity can be observed. The operating condition 3 and 4 has same chamber pressure and fuel temperature but different injection pressures. Therefore, the role of axial momentum of the spray under evaporating but non-flash boiling conditions can be studied. 
The operating condition 5 and 6 demonstrate the non-collapsing spray conditions since the chamber pressure is well above the fuel vapor pressure at $20^{\circ} \mathrm{C}$. Therefore, comparison of condition 4 and 5 allows us to study spray behavior under evaporating and non-evaporating conditions under high injection pressure. Finally, the role of axial spray momentum under non evaporating conditions can be studied under ambient conditions.

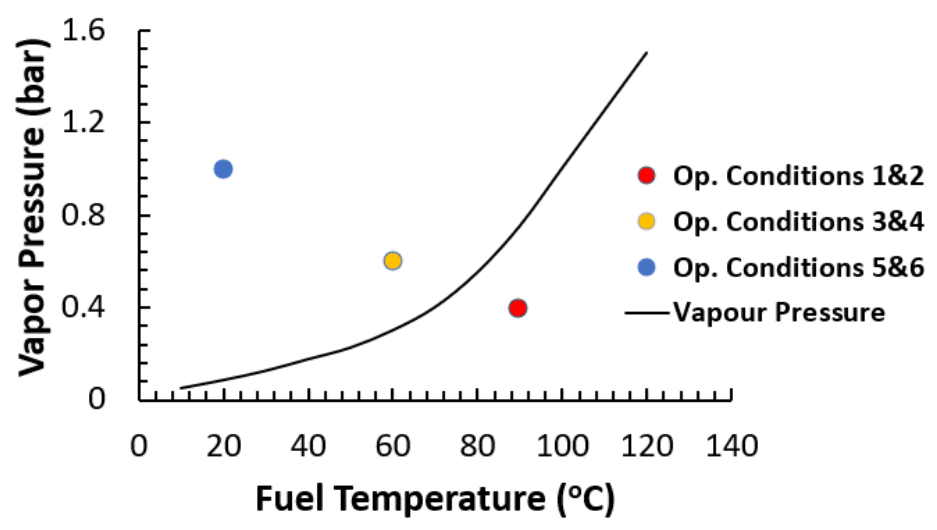

Figure 7: Vapour pressure line of iso-octane for different fuel temperatures

A systematic variation in the fuel and chamber conditions for different injector configurations will allow the identification of important design parameters and boundary conditions. The injection pressure (Pinj), injection fuel temperature (Tfuel), Chamber pressure (Pchamber) a chamber Temperature (Tchamber) control spray shape, penetration, and drop size. These parameters are crucial in enhancing engine performance and emission reduction.

\section{Results and Discussion:}

The results obtained from the investigation of different operating conditions are discussed in this section.

\subsection{Operating Condition 1}

A preheated fuel at $90 \mathrm{oC}$ is injected at a low pressure of 20 bar into a closed chamber having 0.4 bar pressure and $20 \mathrm{oC}$ temperature. The Figure 8 presents the images of all four injectors at $0.5 \mathrm{~ms}$, $1 \mathrm{~ms}$ and $1.5 \mathrm{~ms}$ After the Start of Injection (ASOI). The images reveal that the global spray shapes are significantly modified. The individual spray plumes are merged and a single spray cone appear. High fuel temperature and low chamber and injection pressure promote flash boiling. The high fuel temperature causes the fuel to evaporate inside the nozzle and leads to bubble formation [6, 7]. As soon as the fuel enters the chamber with low pressure, the bubbles instantly collapse causing the 
spray plumes to expand. The spray plumes expand and merge with each other and eventually collapse due to high momentum of the spray cone at the center [11]. Therefore, collapsing sprays penetrate more and may lead to fuel deposition on the piston.

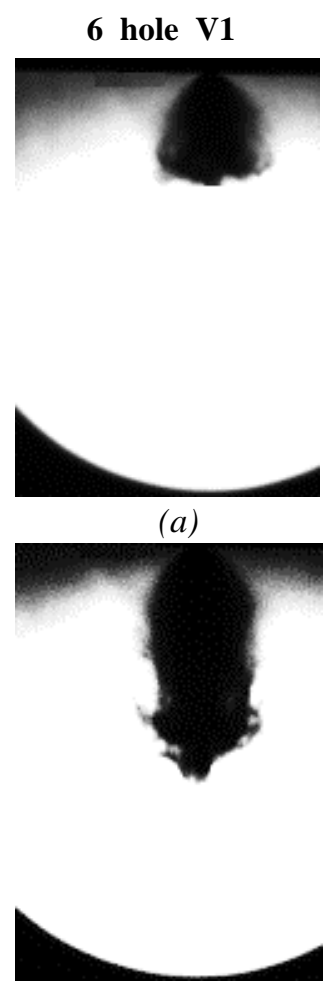

(e)

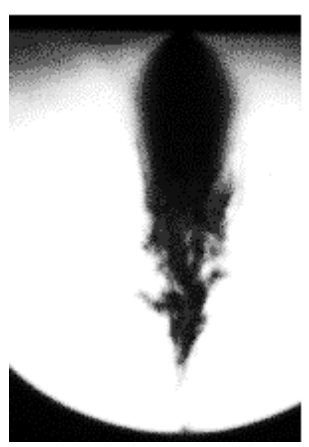

(i)
6 hole V2
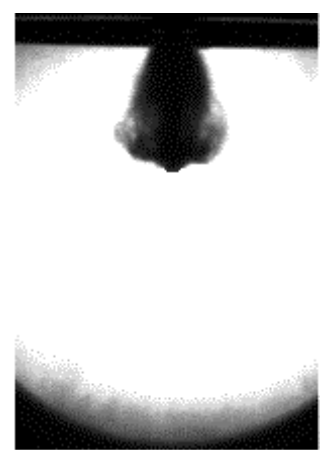

(b)

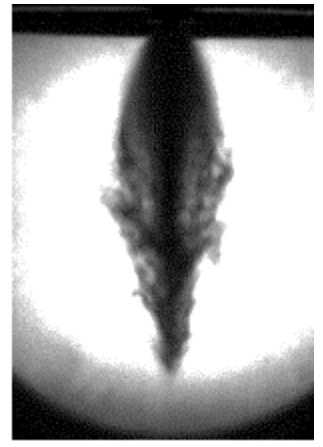

(f)

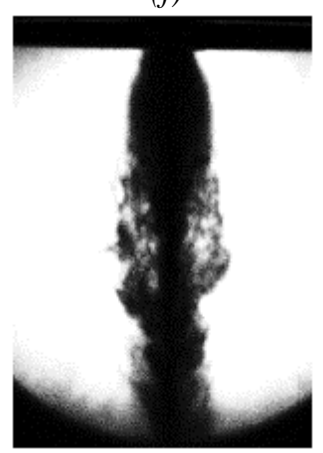

(j)
6 hole V3

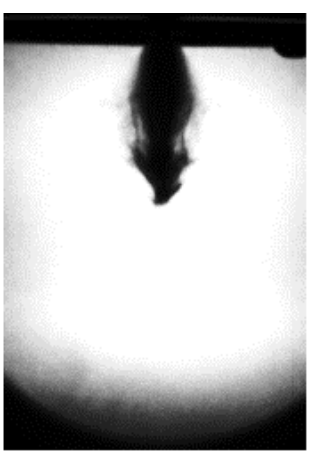

(c)

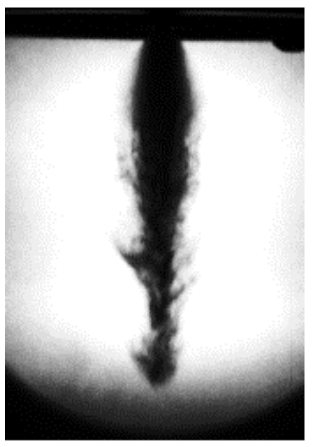

(g)

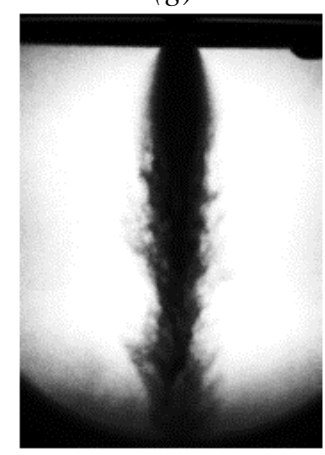

(k)
5 hole
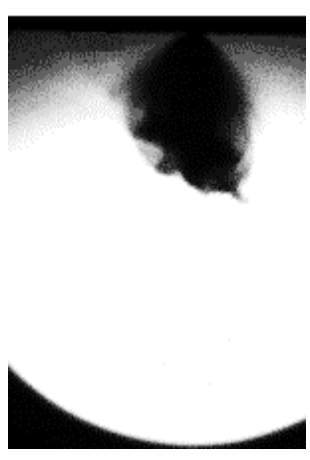

(d)

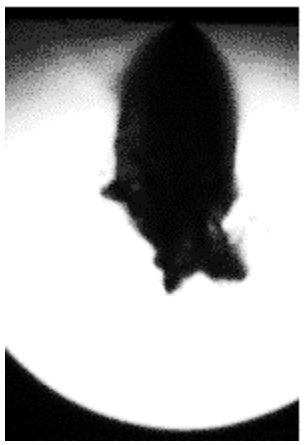

(h)

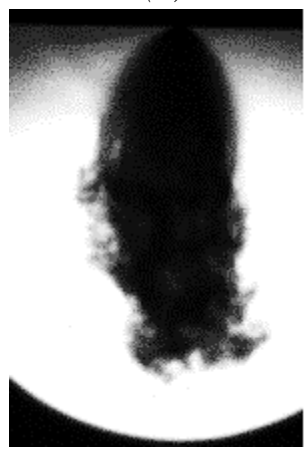

(l)

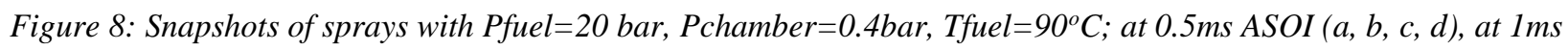
$\operatorname{ASOI}(e, f, g, h)$, at $1.5 m s$ ASOI $(i, j, k, l)$

The spray penetrations and cone angles of sprays from all four injectors are shown in Figure 9 (a $\&$ b). The figures show that the spray penetration of the narrow spray cones penetrate more. The 6 
hole injectors V2 and V3 have the largest penetrations and smallest cone angles. The spray cone angles of V2 and V3 decrease continuously. This highlights the presence of intense jet to jet interactions in 6-hole V2 and V3 injectors. The spray plume penetration of 5-hole injector is initially larger than the 6-hole injector V1. However, toward the end of the injection the penetrations are quite similar. Similar trends in the spray penetrations are also observed in $[16,17]$. This is perhaps due to the asymmetric configuration of the 5-hole injector. The spray from 5-hole injector has more or less constant cone angle which suggests that large spacing between the injection holes limit the effects of flash boiling.

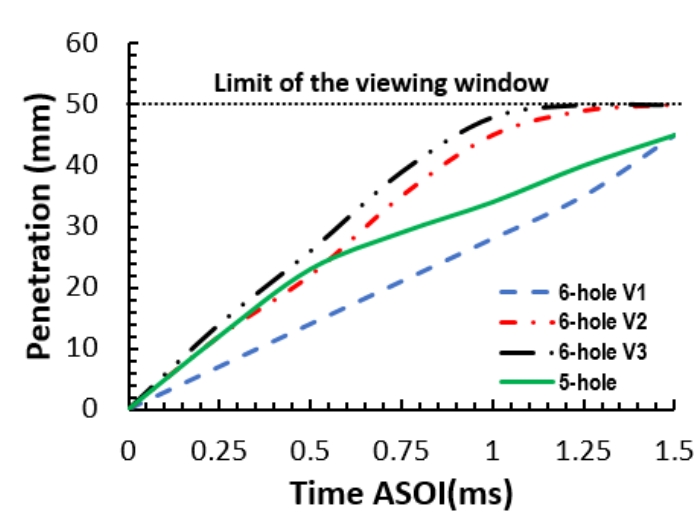

(a)

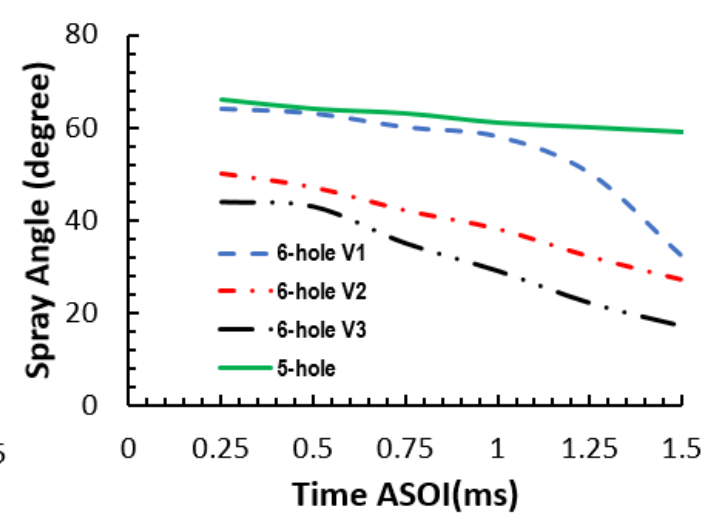

(b)

Figure 9: Spray characteristics at Pfuel $=20$ bar, Pchamber $=0.4$ bar, Tfuel $=90^{\circ} \mathrm{C}$; (a) Penetration (b) Angles

The vapour to liquid fuel ratio, plotted in Figure 10, demonstrates the fuel evaporation is directly proportional to spray cone angle. It is because under flash boiling conditions 5-hole injector produces less collapsing spray due to the larger spray cone angle and injection hole spacing. Therefore, the surface area of the spray increases which promotes evaporation. It is also shown in $[15,18]$ that the variation of temperature under flash boiling conditions increases the width of the spray cone and enhances evaporation rate of the spray. It is also observed from the evaporation rates of six-hole injectors that the spray cone angle also affects the spray penetration rate. However, the combined effect of spray cone angle and injection hole spacing has a much larger effect on the spray evaporation. 


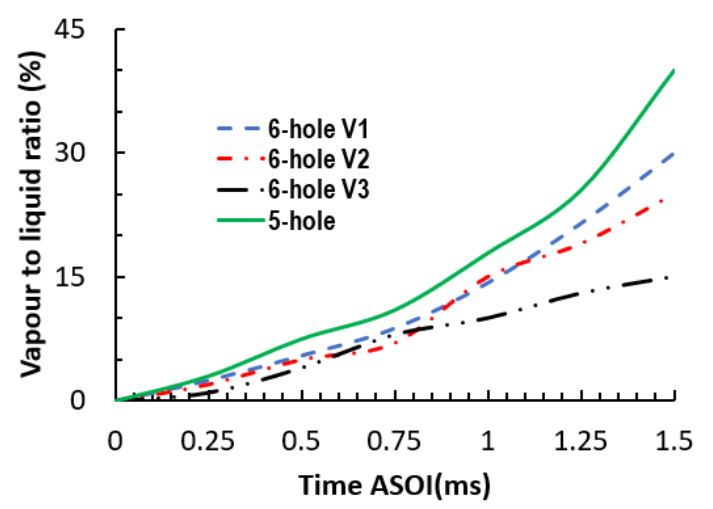

Figure 10: Vapour to liquid fuel ratio at Pfuel $=20$ bar, Pchamber $=0.4 \mathrm{bar}$, Tfuel $=90^{\circ} \mathrm{C}$

\subsection{Operating Condition 2}

The injection pressure is now increased to 50 bar while keeping the other conditions same as operating condition 1 . The chamber pressure is still lower than the vapor pressure at $90^{\circ} \mathrm{C}$ fuel temperature. However, an increase in the fuel injection pressure suggest that the fuel velocity is higher at the exit of the nozzle. Higher fuel injection pressure increases the spray axial momentum in the vicinity of the nozzle which allow the spray plumes to maintain the spray direction longer. Therefore, as seen in Figure 11, both spray penetrations and spray cone angles increase as a result to higher axial momentum. Similar spray behavior is seen in $[19,20]$ where the higher fuel injection pressure delays the spray collapse. Therefore, increase in fuel injection pressure along with increase in fuel temperature and decrease in chamber pressure result in more penetrating sprays.

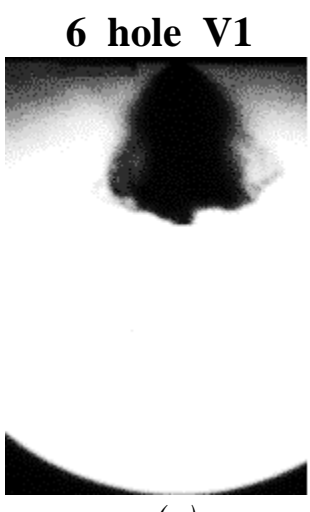

(a)
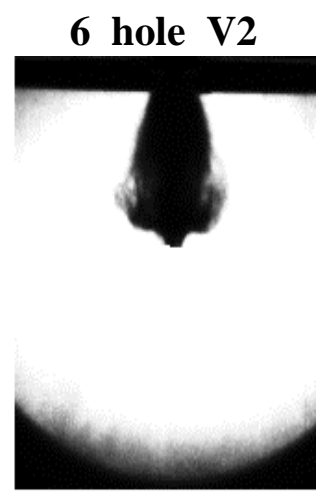

(b)
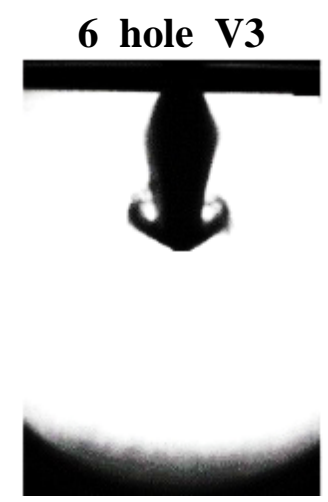

(c)

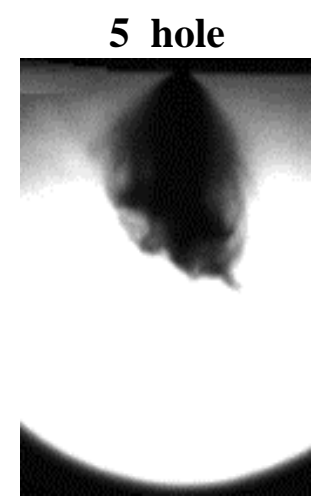

(d) 


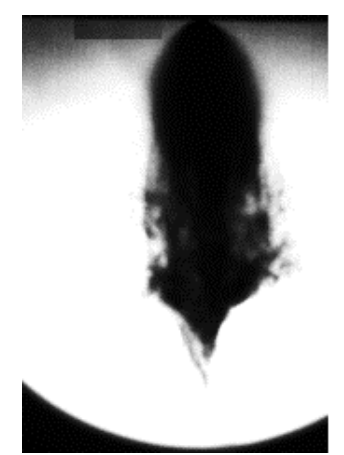

(e)

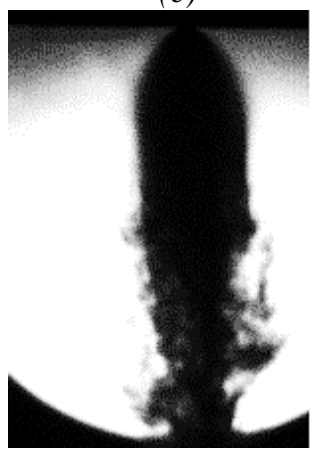

(i)

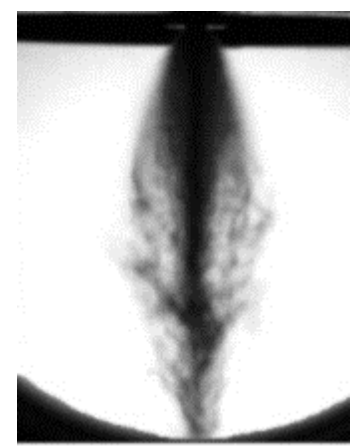

(f)

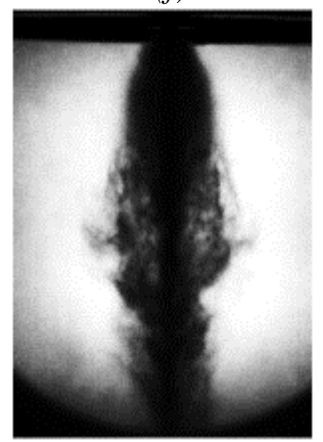

(j)

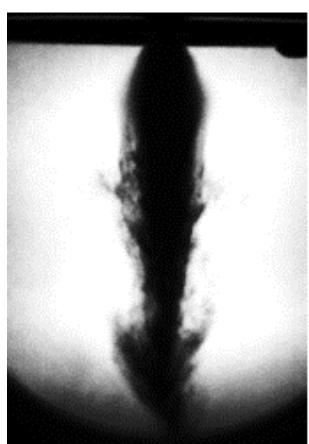

(g)

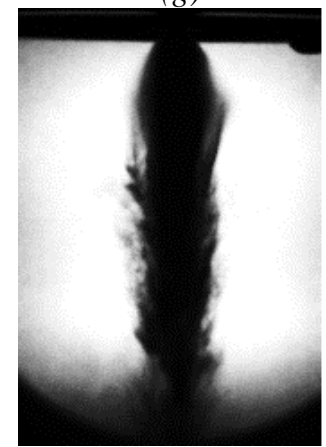

(k)

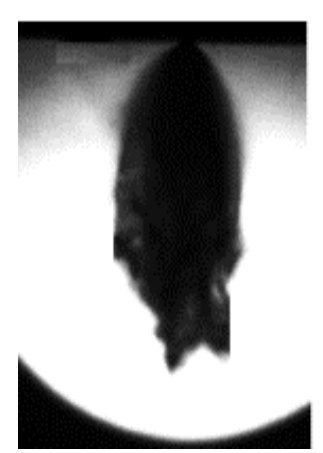

(h)

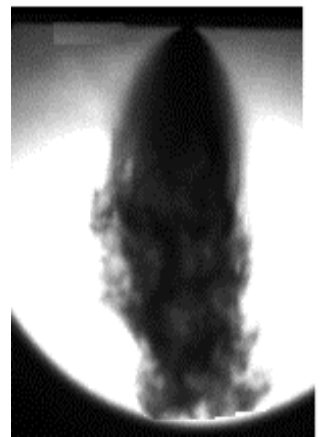

(l)

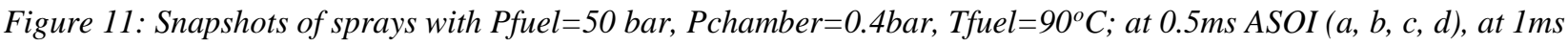
$\operatorname{ASOI}(e, f, g, h)$, at $1.5 m s \operatorname{ASOI}(i, j, k, l)$

The operating condition 1 and 2 both show full collapse of spray. Since the flash boiling process expands the spray plumes which merge with each other and block the gas entrainment from outside. The gas in between the spray plumes is pushed downwards in axial direction creating high pressure region. Therefore, the sprays plumes cannot continue on their path and eventually collapse. This pattern is also observed in $[18,21]$. Therefore, it is important to quantify the variation in the flash boiling effects due to injection pressure. For this purpose, the intensity of spray collapse is quantified from the percentage modification in the spray cone angles.

$$
C I=\frac{\beta_{\text {nominal }}-\beta_{\text {modified }}}{\beta_{\text {nominal }}} \times 100
$$

$\mathrm{CI}$ is the spray collapse intensity percentage, $\beta_{\text {nominal }}$ is the designed spray cone angle, $\beta_{\text {modified }}$ is the modified spray cone angle after spray collapse due to flash boiling. The results from Figure 12 show that the 6-hole V3 has the highest flash boiling intensity and the lowest intensity is of the 5-hole spray. Spray collapse intensity increases with an increase in fuel temperature and decrease in the chamber pressure and fuel injection pressure. The spray cone angle under extreme flash boiling conditions can become very small i.e. $15 \%$ of the original cone angle which means spray collapse intensity can go up to $85 \%$ in such cases. 


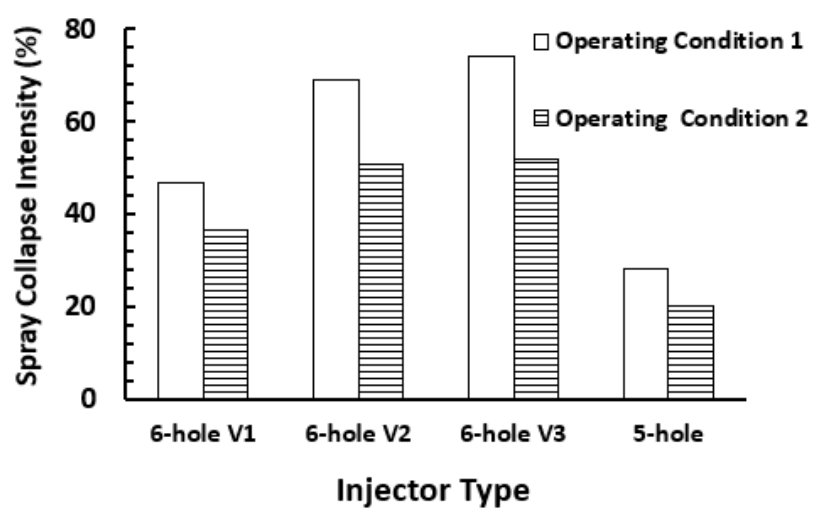

Figure 12: Comparison of spray collapse intensities of different injectors at 20bar and 50bar injection pressures.

The vapor to liquid ratio also increase with an increase in fuel injection pressure due to drop size reduction. At higher injection pressure the liquid drops and ligament experience higher shear stress which enhances droplet breakup mechanism and at high temperatures smaller droplets evaporate quickly [3, 22]. The Figure 13 shows that the evaporation rate of all the sprays is higher than the sprays at 20 bar injection pressure.

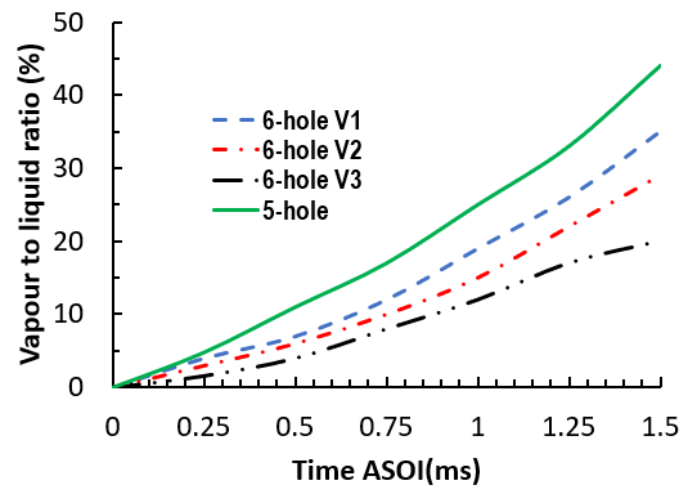

Figure 13: Vapour to liquid fuel ratio at Pfuel $=50$ bar, Pchamber $=0.4 \mathrm{bar}$, Tfuel $=90^{\circ} \mathrm{C}$

\subsection{Operating Condition 3}

The results from first two set of operating conditions suggest that the tendency of spray collapse increases with decrease in chamber pressure and fuel temperature. Third set of conditions has higher chamber pressure and lower fuel pressure presented in Figure 14. When the chamber pressure is higher than the vapor pressure of fuel then full spray collapse does not occur [17, 23]. As expected the tendency of spray collapse vanishes in case of 5-hole however partial collapse in 6-hole V1 and V3 are still visible in Figure 14.

Some important conclusions can be deduced from these results. First of all, the angle of the spray cone is a key factor in initiating or avoiding the spray collapse. The 6-hole V3 injector has narrow spray cone angle than both 6-hole V1 and 5-hole injector therefore it shows higher collapse tendency. 
Second important parameter is the distance between the injection holes. In 5-hole injector larger spacing between the spray plumes along with wider spray cone angle result in minimal spray plume interactions and consequently no spray collapse. This is also confirmed in Figure 15 as 5-hole spray is least penetrating after 6-hole V3 and V1.

6 hole V1

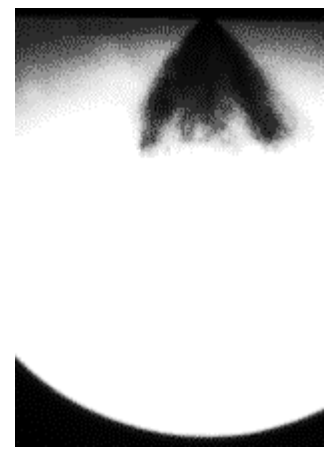

(a)

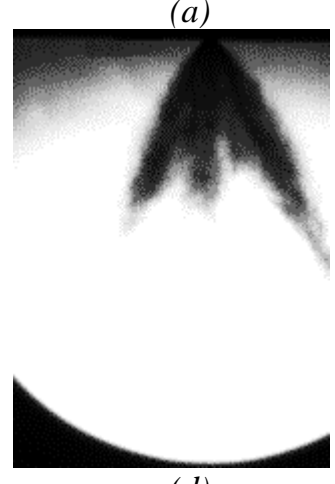

(d)

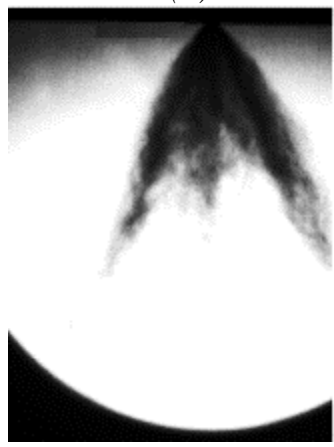

(g)
6 hole V3

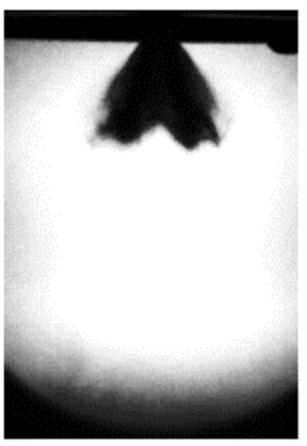

(b)

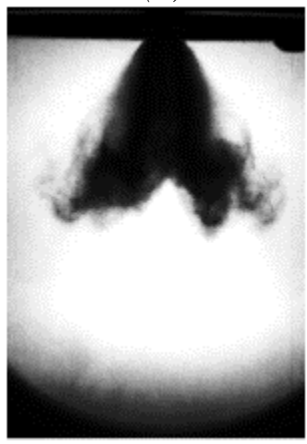

$(e)$

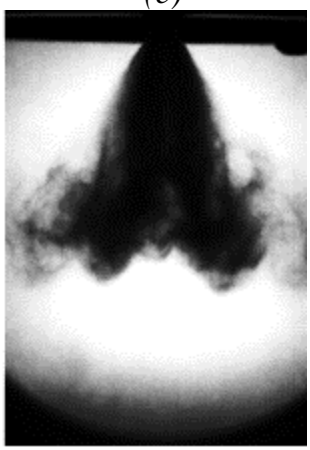

(h)
5 hole

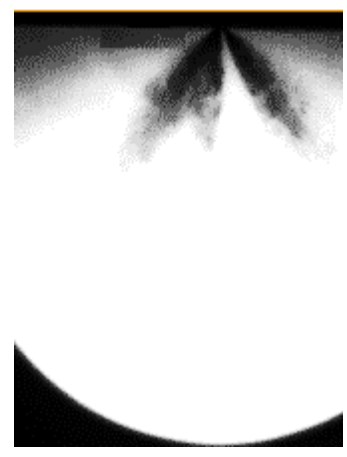

(c)
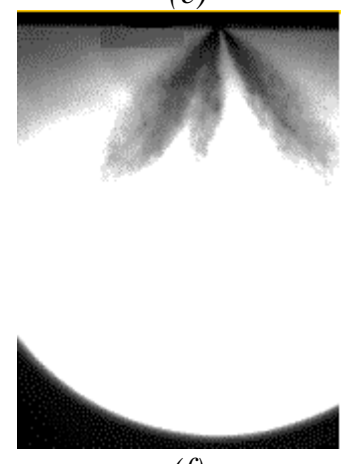

$(f)$
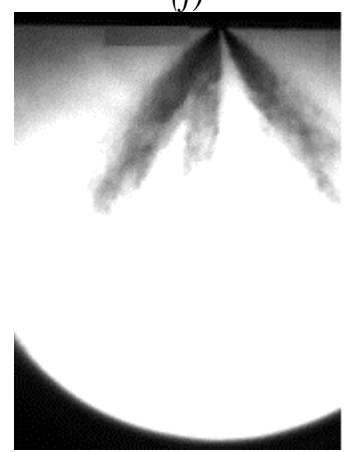

(i)

Figure 14: Snapshots of sprays with Pfuel=50 bar, Pchamber=0.6bar, Tfuel=60 C; at 0.5ms ASOI (a, b, c), at $1 \mathrm{~ms}$ ASOI (d,e, f), at 1.5ms ASOI $(g, h, i)$ 


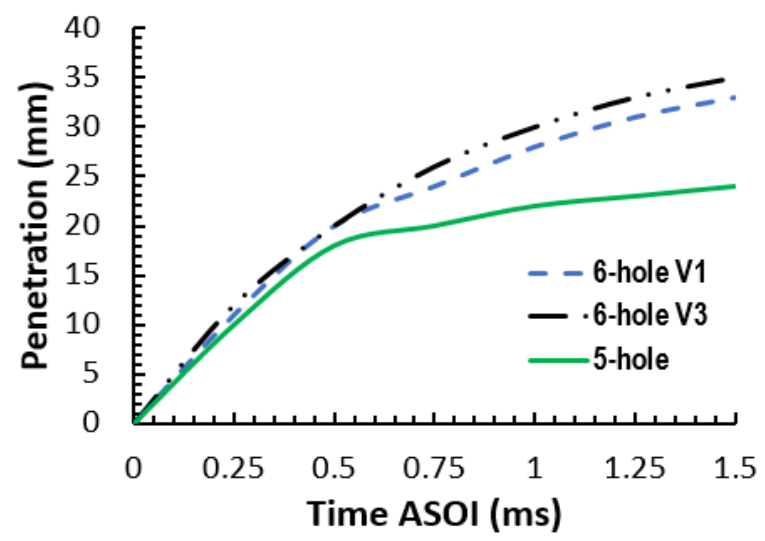

Figure 15: Spray penetration, at Pfuel $=50$ bar, Pchamber $=0.6 \mathrm{bar}$, Tfuel $=60^{\circ} \mathrm{C}$;

The Figure 16 shows vapor to liquid ratio under evaporating but non-flashing conditions. The spray evaporation rate reduces under these conditions in comparison to both operating conditions 1 and 2. However, spray evaporation rate of 5-hole injector is still higher than 6-hole injectors due to reduced jet to jet interactions.

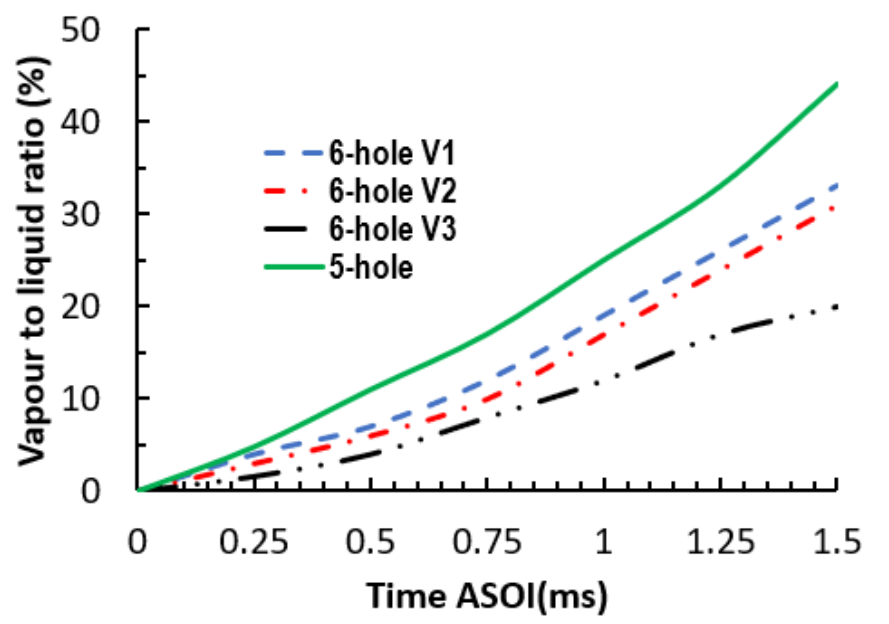

Figure 16: Vapour to liquid fuel ratio at Pfuel $=50 \mathrm{bar}$, Pchamber $=0.6 \mathrm{bar}$, Tfuel $=60^{\circ} \mathrm{C}$

\subsection{Operating Condition 4}

In operating condition 4, the injection pressure is increased to 100 bar while keeping other conditions same as operating condition 3. The increased injection pressure increases the spray penetration and reduces the flash boiling effects as observed in Figure 17 and Figure 18. The spray plumes are segregated and the jet to jet interactions are reduced considerably. The upper part of the spray cone 
of the spray from 6- hole injector V1 shows the merger of the spray plumes due to the expansion of the jets however the momentum of spray individual plumes keep the plumes segregated. The detailed analysis of the air entrainment process and factors that lead to partial collapse of spray are presented in detail in [11]. The spray images of 5-hole spray show that the sprays are well separated without any initial jet to jet interactions.

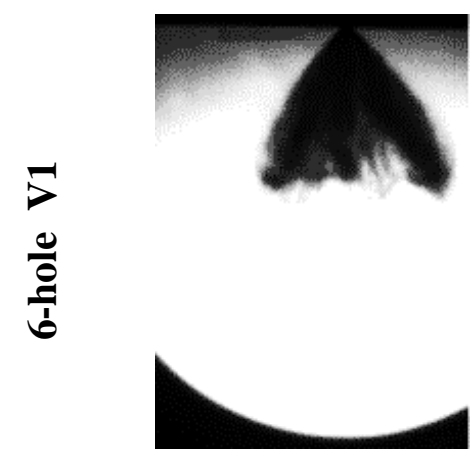

(a)

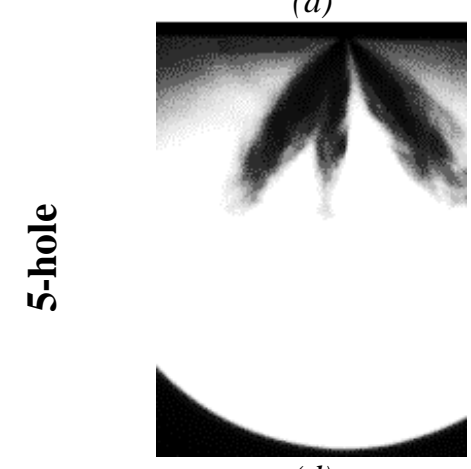

(d)

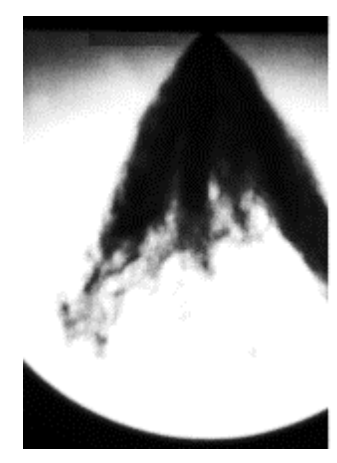

(b)

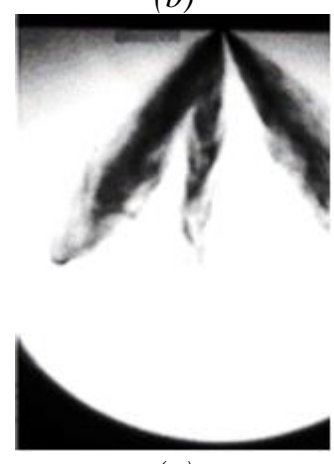

(e)

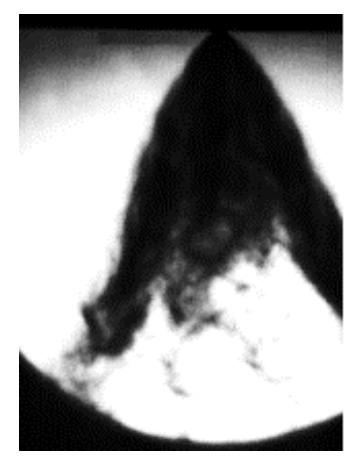

(c)

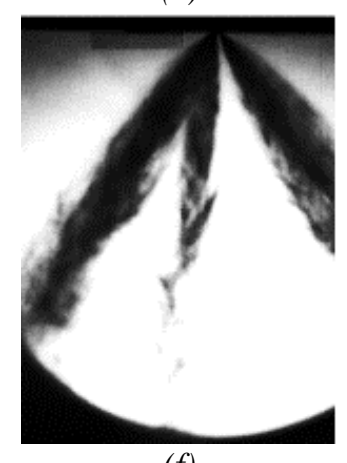

(f)

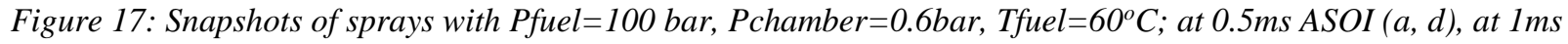
$\operatorname{ASOI}(b, e)$, at $1.5 \mathrm{~ms} \operatorname{ASOI}(c, f)$

The atomization process of segregated spray plumes is much higher in comparison to the spray plumes with high jet to jet interactions $[16,24]$. Consequently, the evaporation rate of segregated spray plume is much higher resulting in reduced spray penetrations. 


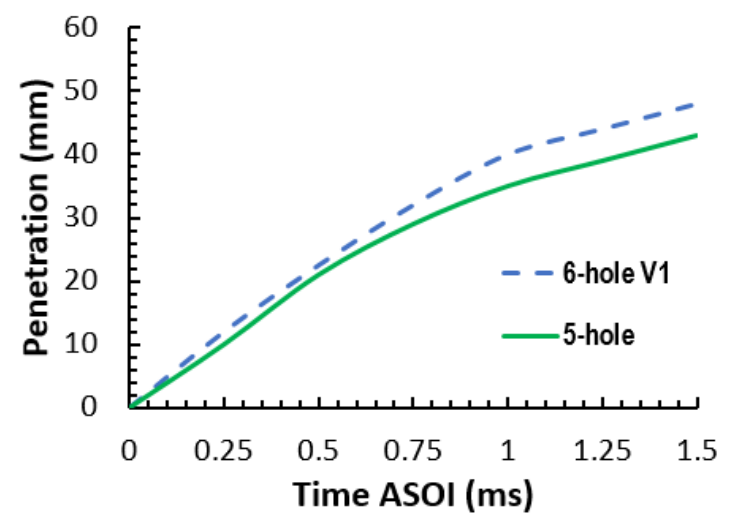

Figure 18: Spray penetration, at Pfuel $=100 \mathrm{bar}$, Pchamber $=0.6 \mathrm{bar}$, Tfuel $=60^{\circ} \mathrm{C}$;

\subsection{Operating Condition 5}

The chamber pressure is now increased to 1 bar while keeping the injection pressure same as in operating condition 4 . The fuel and chamber temperatures are equal to $20^{\circ} \mathrm{C}$. The results in Figure 19 show that the spray collapse cannot be observed any more in neither 6-hole injector nor in 5-hole injector. The tips of the spray plumes of both injectors can easily be identified. However, the 6-hole injector due narrow spray cone angle still show some jet to jet interactions in the upper half of the spray cone.

Generally, larger spray cone angles and smaller individual plume angles keep the spray plumes segregated but these are not always advantageous [15]. During the design of spray injection system for a specific engine it is ensured that the spray plumes do not deposit any fuel on the engine walls, piston, spark plug or the valves. Therefore, the spray cone angles along with individual plumes directions and angles are adjusted accordingly. The optimum injector location and the spray angles are crucial for meeting strict emission requirements these days.

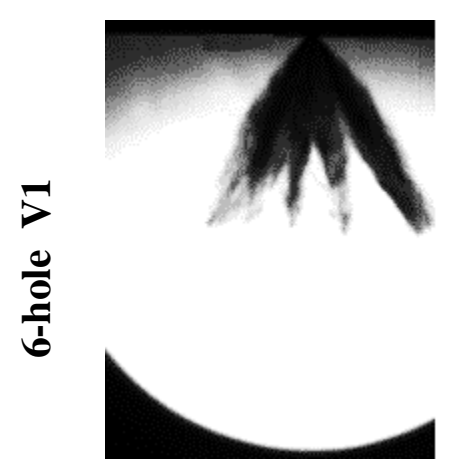

(a)

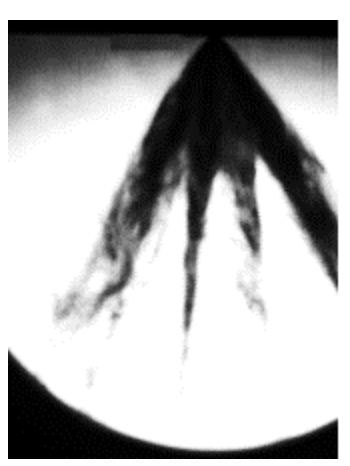

(b)

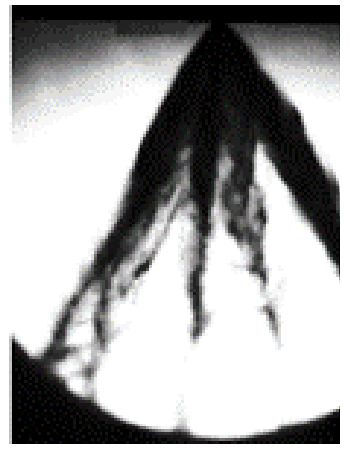

(c) 


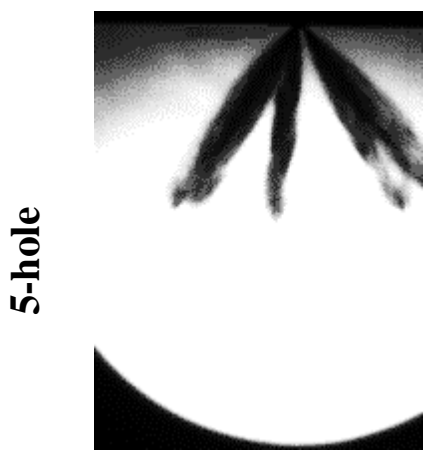

(d)

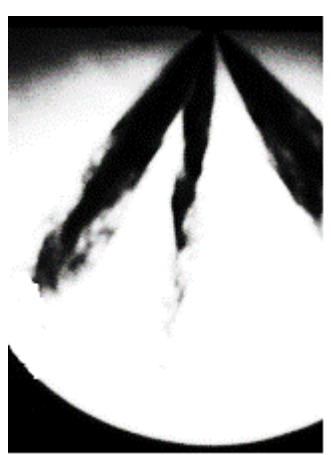

(e)

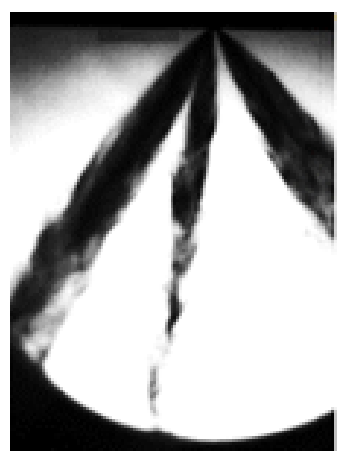

(f)

Figure 19: Snapshots of sprays with Pfuel $=100$ bar, Pchamber=1bar, Tfuel=20 C; at $0.5 \mathrm{~ms}$ ASOI (a, d), at Ims ASOI (b,e), at $1.5 \mathrm{~ms}$ ASOI $(c, f)$

\subsection{Operating Condition 6}

Further increase in spray injection pressure under ambient conditions increase the spray penetrations due to higher injection velocity. The sprays in 6-hole and 5-hole injectors, as shown in Figure 20, are well segregated due to higher spray plume momentum. Also, the spray angles match closely to the prescribed spray cone angles of the respective injectors. This shows that the boundary conditions also play crucial role in achieving the desired targeting of the spray plumes in the engine. In addition to the spray shape, drop diameters are also measured. The drop diameters are measured by Phase Doppler Anemometry (PDA). The drop diameters are measured in terms of Sauter Mean Diameter (SMD) which is the ratio of mean droplet volume to mean droplet surface area. The drop diameter results in Figure 21 suggest that the 5-hole injector produces smallest mean drop sizes. This highlights the importance of segregated spray plumes. The droplet breakup is promoted when the drops are subjected to higher drag [14]. Therefore, it is necessary to keep the spray plumes well segregated.

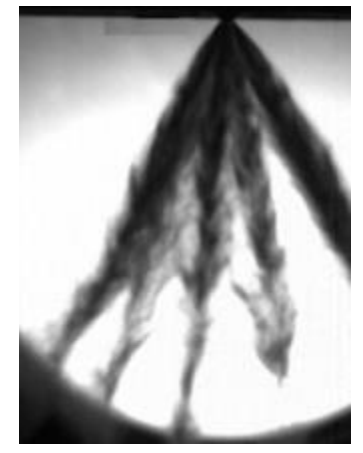

(a)

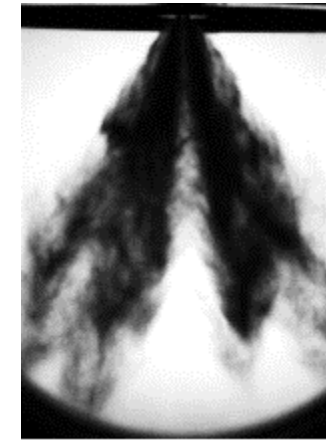

(b)

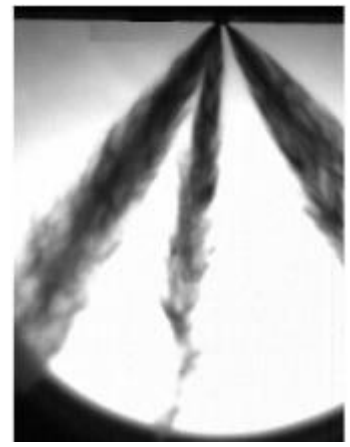

(c)

Figure 20: Snapshots of sprays with Pfuel=150 bar, Pchamber $=1$ bar, Tfuel=20 ${ }^{\circ}$; at $1 \mathrm{~ms}$ ASOI (a) 6-hole V1, (b) 6-hole V3, (c) 5hole 


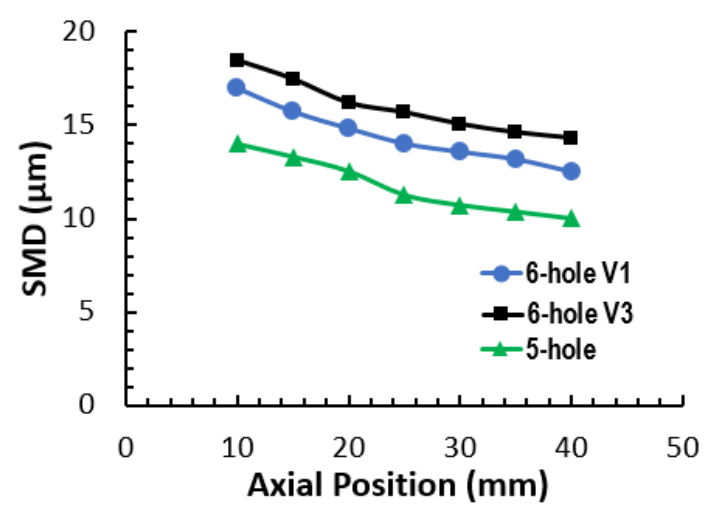

Figure 21: Comparison of drop diameters at different axial locations

\section{Conclusion}

A thorough investigation of multihole GDI injectors under flashboiling, evaporating and nonevaporating conditions has been carried out. Four different configurations of the injectors have been selected for this purpose. Each injector is tested under six different operating conditions. The results highlighted critical design parameter and important boundary conditions that affect the spray characteristics.

1. The sprays from all four injectors showed the collapsing behavior under flash boiling conditions. However, increase in fuel injection pressure showed a decrease in collapse tendency due to increase in the axial momentum of the spray.

2. The sprays with narrower configuration, 6-hole injector V3, showed highest spray collapsing behavior due to higher jet to jet interaction. Collapse Intensity (CI) of 6-hole V3 injector at operating condition 1 has been measured to be $75 \%$ which is much higher than the collapse intensity 6-hole V1 injector that is around 50\%. Therefore, the role of spray cone angle is very important in multihole injectors especially under flash boiling conditions.

3. The distance between injection holes play important role in maintaining the spray shape and limiting the spray penetration. The 5-hole injector avoids full spray collapse in flash boiling conditions. Therefore, the distance between the injection holes is the most important controlling design parameters in flash boiling conditions. The increase in spray cone angles also reduce the spray collapse but its role is always limited due to engine design constraint like the presence of spark plug, valves, cylinder wall etc. 
4. The evaporation rate of 5-hole injector is higher than 6-hole injectors due to less jet to jet interactions. However, higher spray evaporation rate has been observed in the wider configuration amongst the 6-hole injectors.

5. The sprays under evaporating but non-flash boiling conditions showed partial collapse of sprays of 6-hole injectors. However, wider spray cone angle of injector V1 maintained the original direction of the spray plumes while injector V3 could not due to excessive jet to jet interactions. The spray plumes of 5-hole injector remained segregated throughout due to large spray cone angle and more distance between injection holes.

6. The jet to jet interactions of sprays under non-evaporating conditions reduced in six-hole injectors whereas 5-hole injector do not show any jet to jet interactions. Therefore, the drop sizes of 5-hole injector is smaller in comparison to 6-hole injectors.

Chamber temperature and pressure cause the variation in the chamber gas density. Therefore, chamber gas density increases in high load conditions and decreases in low load conditions. In future it would be interesting to study the effects of chamber gas density on the spray characteristics such as axial penetrations, spray plume angles, spray cone angles, and spray evaporation. Furthermore, a continuous fuel injection of the injector, used in this study, can be split in to two or more injections by introducing short delays typically in micro seconds. The split injections would allow the injector to inject the fuel in short bursts which may reduce spray penetration and enhance fuel evaporation.

\section{Statement of Conflict of Interest:}

On behalf of all authors, the corresponding author states that there is no conflict of interest.

\section{References}

1. Alkidas AC, El Tahry SH (2003) Contributors to the Fuel Economy Advantage of DISI Engines Over PFI Engines. SAE Tech Pap Ser. doi: 10.4271/2003-01-3101

2. Piock WF, Befrui B, Berndorfer A, Hoffmann G (2015) Fuel Pressure and Charge Motion Effects on GDi Engine Particulate Emissions. SAE Int J Engines 8:464-473. doi: 10.4271/2015-01-0746

3. Lee S, Park S (2014) Spray atomization characteristics of a GDI injector equipped with a group-hole nozzle. Fuel 137:50-59. doi: 10.1016/j.fuel.2014.07.063

4. Wigley G, Goodwin M, Pitcher G, Blondel D (2004) Imaging and PDA analysis of a GDI spray in the nearnozzle region. Exp Fluids 36:565-574. doi: 10.1007/s00348-003-0690-1

5. Choi D-S, Choi G-M, Kim D-J (2002) Spray structures and vaporizing characteristics of a GDI fuel spray. KSME Int J 16:999-1008. doi: 10.1007/bf02949729

6. Khan M (2014) RANS and LES of multi-hole sprays for the mixture formation in piston engines. Ecole 
Centrale de Lyon

7. Montanaro A, Allocca L (2015) Flash Boiling Evidences of a Multi-Hole GDI Spray under Engine Conditions by Mie-Scattering Measurements. SAE Tech Pap Ser. doi: 10.4271/2015-01-1945

8. Khan MM, Hélie J, Gorokhovski M, Sheikh NA (2017) Experimental and numerical study of flash boiling in gasoline direct injection sprays. Appl Therm Eng 123:377-389. doi: 10.1016/j.applthermaleng.2017.05.102

9. Khan MM, Sheikh NA (2016) Identification and characterization of coherent structures in gasoline injector nozzle flow using proper orthogonal decomposition. J Mech Sci Technol 30:3673-3680. doi: 10.1007/s12206016-0729-x

10. Vairamuthu G, Sundarapandian S, Thangagiri B (2015) Use of calophyllum inophyllum biofuel blended with diesel in DI diesel engine modified with nozzle holes and its size. Heat Mass Transf 52:1005-1013. doi: $10.1007 / \mathrm{s} 00231-015-1623-2$

11. Khan M, Hélie J, Gorokhovski M, Sheikh NA (2017) Air Entrainment in High Pressure Multihole Gasoline Direct Injection Sprays. J Appl Fluid Mech 10:1223-1234. doi: 10.18869/acadpub.jafm.73.241.27628

12. Negro S, Brusiani F, Bianchi GM (2011) A Numerical Model for Flash Boiling of Gasoline-Ethanol Blends in Fuel Injector Nozzles. SAE Int J Fuels Lubr 4:237-256. doi: 10.4271/2011-24-0003

13. Zeng Y, Lee C (2000) Modeling of Spray Vaporization and Air-Fuel Mixing in Gasoline Direct-Injection Engines. SAE Tech Pap Ser. doi: 10.4271/2000-01-0537

14. Bar-Kohany T, Levy M (2016) STATE OF THE ART REVIEW OF FLASH-BOILING ATOMIZATION . At Sprays 26:1259-1305. doi: 10.1615/atomizspr.2016015626

15. Li Y, Guo H, Ma X, et al (2018) Morphology analysis on multi-jet flash-boiling sprays under wide ambient pressures. Fuel 211:38-47. doi: 10.1016/j.fuel.2017.08.082

16. Guo H, Ding H, Li Y, et al (2017) Comparison of spray collapses at elevated ambient pressure and flash boiling conditions using multi-hole gasoline direct injector. Fuel 199:125-134. doi:

10.1016/j.fuel.2017.02.071

17. Huang Y, Huang S, Huang R, Hong G (2016) Spray and evaporation characteristics of ethanol and gasoline direct injection in non-evaporating, transition and flash-boiling conditions. Energy Convers Manag 108:68-77. doi: 10.1016/j.enconman.2015.10.081

18. Montanaro A, Allocca L, Lazzaro M (2017) Iso-Octane Spray from a GDI Multi-Hole Injector under Non- and Flash Boiling Conditions. SAE Tech Pap Ser. doi: 10.4271/2017-01-2319

19. Aleiferis PG, van Romunde ZR (2013) An analysis of spray development with iso-octane, n-pentane, gasoline, ethanol and n-butanol from a multi-hole injector under hot fuel conditions. Fuel 105:143-168. doi:

10.1016/j.fuel.2012.07.044

20. Chen R, Nishida K (2014) Spray evaporation of ethanol-gasoline-like blend and combustion of ethanolgasoline blend injected by hole-type nozzle for direct-injection spark ignition engines. Fuel 134:263-273. doi: 10.1016/j.fuel.2014.05.082

21. Schmitz I, Ipp W, Leipertz A (2002) Flash Boiling Effects on the Development of Gasoline Direct-Injection Engine Sprays. SAE Tech Pap Ser. doi: 10.4271/2002-01-2661 
22. van Romunde Z, Aleiferis PG (2009) EFFECT OF OPERATING CONDITIONS AND FUEL VOLATILITY ON DEVELOPMENT AND VARIABILITY OF SPRAYS FROM GASOLINE DIRECT-INJECTION

MULTIHOLE INJECTORS. At Sprays 19:207-234. doi: 10.1615/atomizspr.v19.i3.10

23. Khan MM, Helie J, Gorokhovski M, et al (2012) Numerical analysis of multihole gasoline direct injection sprays. ICLASS

24. Serras-Pereira J, Aleiferis PG, Richardson D, Wallace S (2008) Characteristics of Ethanol, Butanol, IsoOctane and Gasoline Sprays and Combustion from a Multi-Hole Injector in a DISI Engine. SAE Int J Fuels Lubr 1:893-909. doi: 10.4271/2008-01-1591 